\title{
Fracture resistance of premolars with one remaining cavity wall restored using different techniques
}

\author{
Bağdagül Helvacıoğlu KIVANÇ, Tayfun ALAÇAM and Güliz GÖRGÜL \\ Department of Operative Dentistry and Endodontics, Faculty of Dentistry, Gazi University, 8. cd. 82. sk. 06510 Emek, Ankara, Turkey \\ Corresponding author, Bağdagül Helvacıoğlu KIVANÇ; E-mail: bagdagulkivanc@gmail.com
}

\begin{abstract}
The aim of the study was to compare the fracture resistance of maxillary premolars with one remaining cavity wall restored using different post systems. Forty-eight maxillary premolars were endodontically treated and randomly assigned to four groups for postcore restoration. The first three test groups were restored with polyethylene woven fiber posts, custom-made glass fiber-reinforced composite posts, and titanium posts respectively. In the control Group 4, standardized cavities $(3.5 \times 1.5 \mathrm{~mm})$ were prepared in the palatal canal entrance and filled with a resin composite. All the specimens were then restored with a resin composite crown seated on the post. Load was applied with a stainless steel ball $(1 \mathrm{~mm} / \mathrm{min})$, and the failure modes of all specimens were evaluated. There were no significant differences in fracture resistance and failure mode among the different restorative materials $(p>0.05)$. Within the limitations of this in vitro study, it was concluded that the presence and type of post did not influence the fracture load and failure mode of maxillary premolar teeth with one remaining cavity wall.
\end{abstract}

Keywords: Endodontically treated teeth, Fiber-reinforced composite post, Fracture resistance

\section{INTRODUCTION}

Deep cavities with one wall remaining are susceptible to fracture. Hence, to ensure a good long-term prognosis with respect to these teeth, they need special attention and consideration during the decision-making process of their restorative treatment options. Owing to their extreme vulnerability, debate abounds on the appropriate treatment approaches for these teeth.

According to Peroz et al. ${ }^{11}$, a post should be inserted if only one cavity wall remains. On the post material, fiber-reinforced composite (FRC) posts have been the preferred choice for restoration of these teeth for both esthetic and mechanical reasons. On mechanical reasons for FRC posts, laboratory-based studies have shown that these posts have a high tensile strength ${ }^{2)}$ and a modulus of elasticity similar to that of dentin ${ }^{3}$. It is thought that FRC posts flex under load, thereby leading to an improved stress distribution between post and dentin ${ }^{4-77}$.

On post fit within the root canal, custom-made polyethylene fibers and E-glass fibers allow adjustment of post geometry to the anatomy of the root canal rather than adjustment of the root canal to the geometry of a prefabricated post. This is a very advantageous property over the need to prepare post spaces that fit prefabricated posts. Furthermore, the post and restorative coronal segment could be fabricated using similar materials in subsequent procedures within the same session, thus saving time.

On the survival rate of endodontically treated teeth, it has emerged that preserving sound tooth structure is key to improving their longevity ${ }^{8,9)}$. In retrospective clinical reports ${ }^{10,11}$, premolars were found to be the most frequently fractured teeth. However, endodontically treated teeth with MO/DO or MOD cavity restored with a composite resin without cuspal overlay were found to survive for years ${ }^{12)}$. As for endodontically treated premolars with one remaining cavity wall restored with or without posts, information is scarce to date.

Therefore, the aim of the present study was to evaluate the fracture resistance of endodontically treated maxillary premolars with one remaining cavity wall restored using two types of custom-made FRC posts, and then compare their performance against that of titanium post and direct composite restorations.

\section{MATERIALS AND METHODS}

Tooth specimens

Forty-eight freshly extracted, single-rooted, mature, human, maxillary premolars with double canals were selected for this study. The teeth were of similar dimensions and were without caries and abrasion cavities. The teeth were cleaned of debris and soft tissue remnants and then stored in $0.1 \%$ thymol solution at room temperature.

\section{Access cavity preparation}

The root canals were enlarged to the apical foramen with $\mathrm{K}$ files to size 50. A standard flare was produced by the insertion of \#3 Gates-Glidden drill (Dentsply/ Maillefer, Ballaigues, Switzerland). After intermittent rinsing with $2.5 \% \mathrm{NaOCl}$, the canals were dried with paper points (Union Broach Co., Long Island City, NY, USA) and obturated with AH26 sealer (Denstply/ Maillefer) and gutta-percha (DiaDent, Seoul, Korea) using cold lateral condensation.

Palatal cusps were removed and the cavities were prepared using a diamond fissure bur (Komet 837/016Brasseler, Lemgo D), whereby the thickness of the 


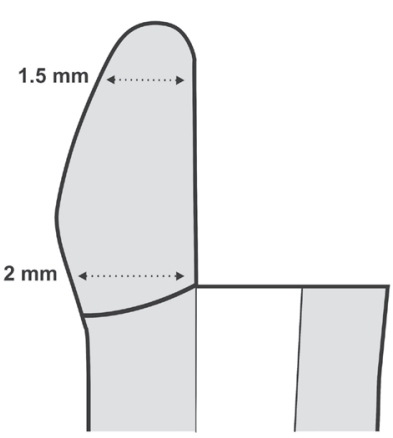

(a)

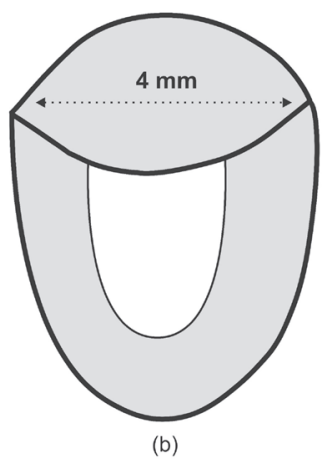

Fig. 1 Schematic representation of cavity in premolar teeth: (a) Proximal view; b) Occlusal view.

buccal wall measured $1.5 \mathrm{~mm}$ at the occlusal surface and $2 \mathrm{~mm}$ at the cementoenamel junction (CEJ) buccolingually and $4 \mathrm{~mm}$ mesio-distally (Figs. 1a and b). The cavity floor was perpendicular to the long axis of the tooth. To standardize the root canal length, the palatal roots were cut to a uniform length of $14 \mathrm{~mm}$.

To ensure uniform cavity dimensions, the lengths and the largest bucco-palatal and mesio-distal widths of the roots were measured with a caliper. The mean values of the dimensions were: bucco-palatal width at $8.1 \mathrm{~mm}$ (SD: 0.3) and mesio-distal width at $4.8 \mathrm{~mm}$ (SD: 0.5). The roots were then randomly assigned to four groups of 12 specimens each, whereby the mean root sizes of the four groups did not differ significantly (ANOVA, $p>0.05$ ).

\section{Experimental groups of this study}

In this study, three different types of prefabricated post materials were evaluated, namely: Group 1 Polyethylene woven fiber post (Ribbond (Thin), Ribbond Inc., Seattle, WA, USA); Group 2 -Custom-made glass FRC post (everStick post (1.5 mm diameter), Stick Tech Ltd., Turku, Finland); and Group 3 -Titanium post (Filpost (1.3 mm diameter), Filhol Dental, Baltimore, MD, USA). For the teeth in Group 4 which served as a control group, direct composite build-ups were constructed without use of any other restorative auxiliary.

In terms of post space preparation for Groups 1 to 3, 10-mm-deep standard post spaces as measured from the palatal CEJ were prepared using \#3 Gates-Glidden drill, leaving $4 \mathrm{~mm}$ of gutta-percha apically. Standardized cavities $(3.5 \mathrm{~mm}$ depth and $1.5 \mathrm{~mm}$ diameter) in the palatal canal entrance were made using \#5 Gates-Glidden and \#6 ParaPost drills (Coltene/Whaledent, Langenau, Germany). All posts were placed to the total depth of the prepared post spaces and handled according to the manufacturers' instructions. In Group 4 (control), no post space preparation was made.

1. Group 1: Polyethylene woven fiber post

The polyethylene woven fiber (Ribbond) was cut to a length of $26 \mathrm{~mm}$. Length of the post space was doubled, estimated core length was added and the necessary length of the woven fibers determined. The fibers were then cut with special scissors according to the determined length.

The ribbon material was soaked in an unfilled resin (Clearfil SE Bond, Kuraray, Osaka, Japan). The woven fiber saturated with the resin was wrapped and condensed tightly into the canal space using an endodontic plugger. Excess resin was removed, and free ends of the fiber were twisted and condensed into the canal. The entire fiber resin post was then cured for 40 seconds.

2. Group 2: Custom-made glass FRC post

Custom-made glass FRC posts (everStick) were cut to a length of $13 \mathrm{~mm}$. The material was fitted into the root canal and further adapted to the cavity by gently pressing with a plugger. The whole system was initially light-cured for 20 seconds. Then, the polymerized material was removed from the canal, light-cured outside the canal for 40 seconds, and reinserted into the canal.

To fill the voids inside the canal along the customized post, an additional bundle of preimpregnated glass fibers was placed on the post surface and light-cured for 20 seconds. Then, the FRC post was removed from the canal and subjected to a final light-curing of 40 seconds. After which, the FRC post system was wetted with a resin (Stick Resin, Stick Tech Ltd.) and protected from any light source while the cement was being prepared.

3. Group 3: Titanium post

For the titanium posts [Filpost $(1.3 \times 16 \mathrm{~mm})$ ] used in this study, the coronal part was marked at a point which was $13 \mathrm{~mm}$ from the apical end. The marked coronal part was cut using a water-cooled diamond bur to standardize the root length.

\section{Restoration with post and crown}

Before post cementation, the canal was cleaned with $2.5 \%$ sodium hypochlorite, rinsed with water spray for 10 seconds, and then dried with paper points for 5 seconds. A self-etching primer (Clearfil SE Bond Primer, Kuraray) was applied to the dowel space walls for 30 seconds and gently air-dried. After priming, an adhesive (Clearfil SE Bond, Kuraray) was applied to the walls, which was thinned using a brush and lightpolymerized for 20 seconds. For post cementation, a dual-cure resin cement (Panavia F, Kuraray) was mixed and inserted into the dowel space using a lentulo spiral. A thin layer of cement was also coated on the post surface, and the post was seated in place using finger pressure for 10 seconds. Excess cement was removed, and the whole post system was light-cured for 40 seconds from the occlusal direction.

In Groups 1 to 3, standardized restorations were made using a composite resin (Clearfil Photo Posterior, Kuraray). Before composite resin crown restoration, the self-etching primer and adhesive were applied on the cavity floor and the remaining dentin surfaces of 
the buccal wall. After which, the first layer of composite resin was applied around the post and lightcured for 40 seconds. To obtain standardized crowns, preformed, transparent, polycarbonate crowns (Ib-Swiss Crowns, Berg, Switzerland) were used. To modify the strip crowns for cavities with buccal cusps only, a 2$\mathrm{mm}$ buccal part of each strip crown was removed. The strip crown was then filled with composite resin, positioned over the tooth and held in place with finger pressure, and light-cured for 40 seconds. Finally, the cervical outline of the composite resin crown and the restoration surface were finished using Sof-Lex disks (3M ESPE, St. Paul, MN, USA).

In Group 4 (control), no other retentive auxiliaries were used apart from the adhesive. The application procedure of primer and adhesive to the dentin surfaces of the cavities was identical to Groups 1-3. After which, the composite resin (Clearfil Photo Posterior, Kuraray) was inserted in two equal masses of increments so that each part had a depth of approximately $1.75 \mathrm{~mm}$. Each increment was placed and light-cured successively. Standardized crowns were obtained using polycarbonate crowns filled with composite resin.

\section{Failure load testing}

All specimens were stored in a saline solution at $37^{\circ} \mathrm{C}$ for 1 week and subjected to 500 thermal cycles at $5^{\circ} \mathrm{C}$ and $55^{\circ} \mathrm{C}$. Copper rings were filled with an autopolymerizing resin (Meliodent, Bayer UK Ltd., Newbury, UK), and the teeth were embedded in the resin up to the CEJ level. The copper rings were then placed in a universal testing machine (Autograph AG10kNIS, Shimadzu, Kyoto, Japan) with the long axis of the roots at an angle of $30^{\circ}$ to the load direction (Fig. 2). A stainless steel ball (4 $\mathrm{mm}$ diameter) was used to load the specimens until fracture, with a crosshead speed of $1 \mathrm{~mm} / \mathrm{min}$. Loading site was the central fissure of the occlusal surface, and the fracture load for each tooth was recorded.

After fracture, all specimens were removed from the acrylic resin and assessed for failure mode. "Favorable failures" were defined as repairable failures, including retention failures and fractures of the root above the level of bone simulation. "Unfavorable failures" were defined as irreparable failures such as root fractures below the level of bone simulation ${ }^{13)}$ (Fig. $3)$.

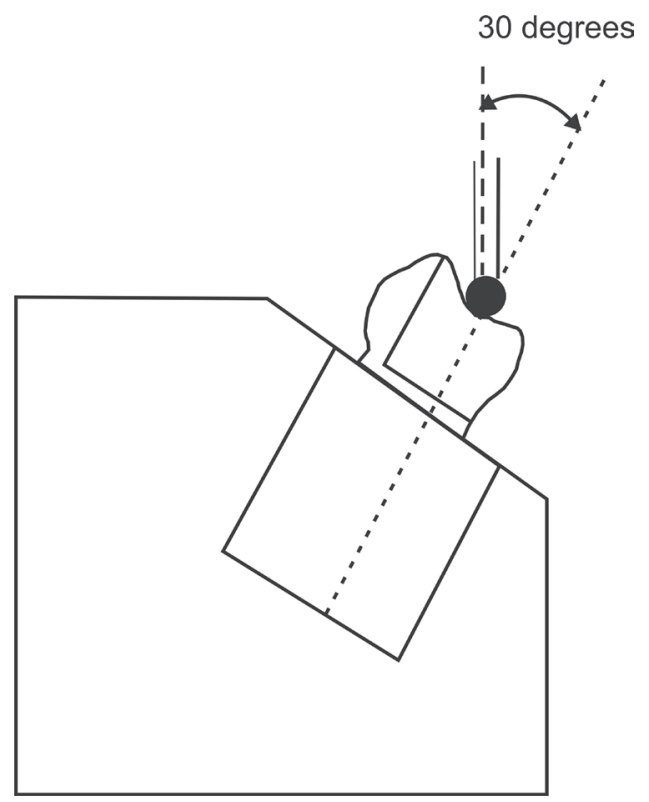

Fig. 2 Experimental method used in this study to determine fracture strength (failure load test).

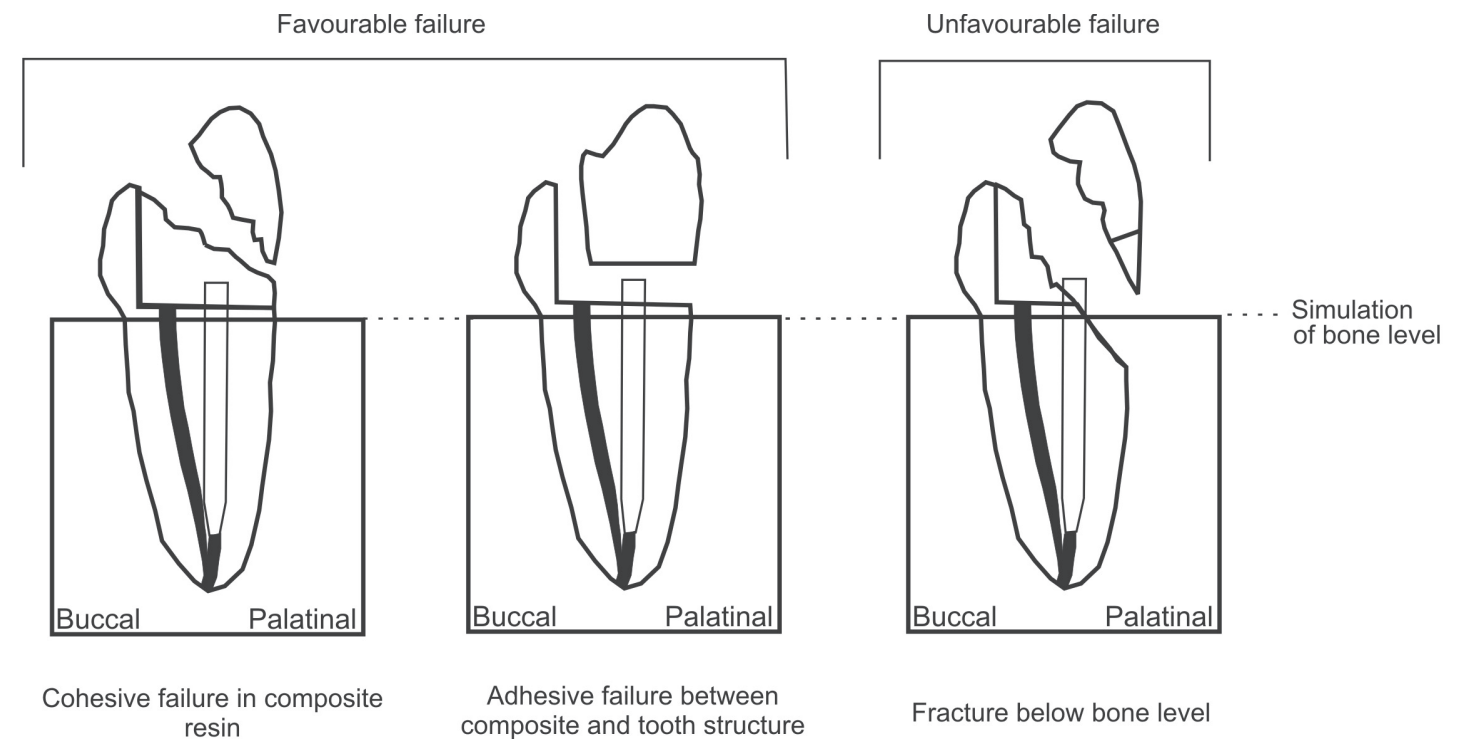

Fig. 3 Schematic representation of the observed failure modes of fractured specimens. 


\section{Statistical analysis}

The fracture load data were statistically analyzed using an analysis of variance (one-way ANOVA), with a value of $p<0.05$ indicating statistical significance. The failure modes were statistically analyzed using the nonparametric Kruskal-Wallis test. All analyses were performed using SPSS version 15.0 (SPSS Inc., Chicago, IL, USA).

\section{RESULTS}

Figure 4 shows the mean failure load values $(\mathrm{N})$ of all the experimental groups in this study. Mean failure load value was 827.25 N (SD: 275.52) for Group 1 (Ribbond), 936.58 N (SD: 299.83) for Group 2 (everStick), 891.50 N (SD: 243.17) for Group 3 (Filpost), and $920.33 \mathrm{~N}$ (SD: 162.24) for Group 4 (direct composite). One-way ANOVA indicated that there were no significant differences $(p>0.05)$ in fracture resistance among the four experimental groups.

Table 1 shows the failure mode results of all the experimental groups in this study. Similarly, there were no significant differences in failure mode among the groups $\left(p=0.804, x^{2}=0.988\right)$ and that many failures were classified as "favorable" in all the groups.

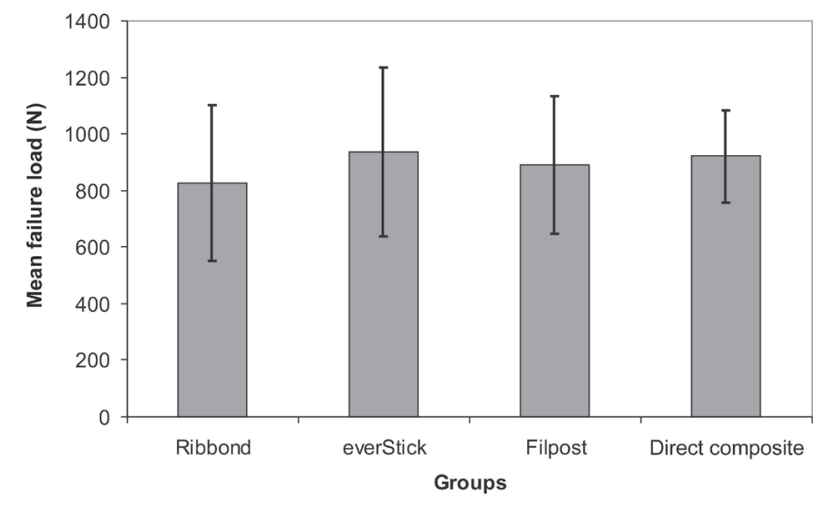

Fig. 4 Mean failure load values (N) of the experimental groups of this study.

\section{DISCUSSION}

It is believed that the prognosis of endodontically treated teeth depends not only on the treatment itself, but also on the material applied and the technique performed for the proper restoration of the coronal cavity $^{1)}$. Choosing the best technique and material according to functional demands and determining the amount of remaining tooth structure for optimum strength against fracture are key factors for success. Against this background, different materials and restorative techniques have been proposed in recent years to improve the therapeutic success of teeth with major structural loss ${ }^{14-17)}$.

Studies have evaluated the fracture resistance of post-retained direct restorations. Several authors reported that high fracture resistance was obtained when the elastic moduli of both post and dentin were compatible ${ }^{2,8,18-20)}$. It is believed that the creation of a mono-block dentin-post-core system through dentinal bonding would allow better distribution of applied forces evenly along the root ${ }^{21)}$. However, a recent literature review demonstrated conflicting results, revealing a slight tendency towards higher fracture resistance of metal posts compared to FRC posts ${ }^{22)}$. In several other studies, FRC posts were also shown to have lower fracture strength than metal posts ${ }^{5,23,24)}$. According to Rosentritt et al. ${ }^{25)}$, increasing the elasticity of the post led to reduced fracture strength of the whole system. They also concluded that the posts stabilized the entire system and thereby partially compensated for the stress on the adhesive composite ${ }^{25)}$.

Contrary to the claim that metal posts have higher fracture resistance than FRC posts, another laboratory study on core restorations without crown coverage for root-filled incisors showed no differences in fracture resistance between custom-made polyethylene woven FRC post and cast post ${ }^{7}$. In this study, similar result was obtained in that the fracture resistance of titanium post-restored teeth was not significantly different $(p>0.05)$ from that restored with glass FRC post, although the elastic modulus of titanium (metallic) post was higher than that of dentin.

Table 1 Incidence rates of failure modes (n) in the four experimental groups of this study

\begin{tabular}{lccc}
\multicolumn{1}{c}{ Group } & $\begin{array}{c}\text { Above bone level; cohesive } \\
\text { failure in composite resin } \\
\text { (Favorable) }\end{array}$ & $\begin{array}{c}\text { Above bone level; adhesive } \\
\text { failure between composite } \\
\text { resin and tooth structure } \\
\text { (Favorable) }\end{array}$ & $\begin{array}{c}\text { Below bone level } \\
\text { (Unfavorable) }\end{array}$ \\
\hline $\begin{array}{l}\text { Polyethylene woven fiber } \\
\text { (Ribbond) }\end{array}$ & 5 & 5 & 2 \\
$\begin{array}{l}\text { Custom-made FRC post } \\
\text { (everStick) }\end{array}$ & 3 & 6 & 3 \\
$\begin{array}{l}\text { Titanium post } \\
\text { (Filpost) }\end{array}$ & 4 & 6 \\
$\begin{array}{l}\text { All composite restoration } \\
\text { (Control) }\end{array}$ & 5 & 5 & 2 \\
\hline
\end{tabular}


In this study, the fracture resistance of teeth restored with composite resin crowns with or without posts was almost similar. This finding agreed with the studies of Krejci et al. ${ }^{26)}$ and Fokkinga et al. ${ }^{14)}$, which concluded that the teeth restored with resin composite crowns without posts had similar fracture resistance and failure modes as those restored with different types of posts. On the tendency of tooth specimens without posts to exhibit a higher fracture resistance, it might be attributed to the presence of a thicker bulk of composite ${ }^{14)}$.

In the post and core restoration of endodontically treated teeth, esthetic consideration also plays an important part in the choice of the type of post. In this study, different esthetic post systems were used and compared against titanium post. It is recognized and agreed that teeth restored with tooth-colored posts have superior esthetics compared with metallic post systems ${ }^{27}$. This is because although titanium is a biocompatible material, its metallic gray color may be visible through the gingival tissue, thereby having a negative impact on clinical decision-making ${ }^{28,29)}$.

In the present study, maxillary premolars were used to compare the appropriateness of different restorative options with regard to mechanical loading in cavities with buccal cusps only. This is chiefly because in the clinical setting, a high incidence of fractures is reported for maxillary premolars and that molars of the same dental arch have presented similar fracture rates ${ }^{30)}$. Fracture analysis revealed that the lingual cusp fractured more frequently in maxillary premolars under compressive loading ${ }^{31)}$. Similarly, an in vivo study by Eakle et al. ${ }^{32)}$ reported that the lingual cusps of maxillary premolars fractured more often than the buccal cusps. Therefore, in this study, maxillary premolars with only one remaining buccal cavity wall were used in order to compare the fracture resistance of such endodontically treated teeth restored with or without posts and with a direct composite resin crown.

In this study, no crown coverage was performed. This experimental strategy was used because in a three-year clinical study by Mannocci et al. ${ }^{33)}$, there were no statistically significant differences in survival rate between the endodontically treated premolars restored with posts and direct composite restorations and with or without metal-ceramic crowns. In other words, it is implied that for endodontically treated premolar teeth with only one remaining cavity wall, an adhesive technique without any crown coverage might be a viable, economical, and tooth-saving alternative to the more expensive and less conservative crown coverage approach.

On fracture mode, a vast majority of the specimens in this study exhibited favorable failures in all the experimental groups. The rates of cohesive and adhesive failures were also similar. Results of this study seemed to suggest that post placement in severely damaged, root-filled, maxillary premolars did not provide any additional benefit over all-composite restorations.
In the oral cavity, the load capability of a rootfilled tooth is influenced by myriad factors: the number of adjacent teeth, the number of occlusal contacts, tooth position in the dental arch, crown placement, apical status of abutment, degree of severity of collagen degradation, degree of intermolecular crosslinking of root dentin, and the amount of lost tissue being the most crucial factor ${ }^{34)}$. The present study was carried out in vitro and the failure loading test was performed at 1 week after restorations were placed. During the 1-week storage, thermocycling was performed to simulate moisture and temperature changes encountered intraorally. Nonetheless, controlled clinical trials of endodontically treated and restored teeth with one remaining cavity wall must be carried out to validate the in vitro results.

\section{CONCLUSION}

Within the limitations of this in vitro study, the presence and type of post did not influence the fracture load nor the failure mode of single-rooted maxillary premolar teeth with only buccal cusp remaining.

\section{REFERENCES}

1) Peroz I, Blankenstein F, Lange KP, Naumann M. Restoring endodontically treated teeth with posts and cores - a review. Quintessence Int 2005; 36: 737-746.

2) King PA, Setchell DJ. An in vitro evaluation of a prototype CFRC prefabricated post developed for the restoration of pulpless teeth. J Oral Rehabil 1990; 17: 599-609.

3) Asmussen E, Peutzfeldt A, Heitmann T. Stiffness, elastic limit, and strength of newer types of endodontic posts. J Dent 1999; 27: 275-278.

4) Bateman G, Ricketts DN, Saunders WP. Fibre-based post systems: a review. Br Dent J 2003; 195: 43-48.

5) Newman MP, Yaman P, Dennison J, Rafter M, Billy E. Fracture resistance of endodontically treated teeth restored with composite posts. J Prosthet Dent 2003; 89: 360-367.

6) Maccari PC, Cosme DC, Oshima HM, Burnett LH Jr, Shinkai RS. Fracture strength of endodontically treated teeth with flared root canals and restored with different post systems. J Esthet Restor Dent 2007; 19: 30-36.

7) Eskitascioglu G, Belli S, Kalkan M. Evaluation of two post core systems using two different methods (fracture strength test and a finite elemental stress analysis). J Endod 2002; 28: 629-633.

8) Trabert KC, Caput AA, Abou-Rass M. Tooth fracture - a comparison of endodontic and restorative treatments. J Endod 1978; 4: 341-345.

9) Sorensen JA. Preservation of tooth structure. J Calif Dent Assoc 1988; 16: 15-22.

10) Rud J, Omnell KA. Root fractures due to corrosion: diagnostic aspects. Scand J Dent Res 1970; 78: 397-403.

11) Tamse A, Fuss Z, Lustig J, Kaplavi J. An evaluation of endodontically treated vertically fractured teeth. J Endod 1999; 25: 506-508.

12) Hansen EK, Asmussen E. In vivo fractures of endodontically treated posterior teeth restored with enamelbonded resin. Endod Dent Traumatol 1990; 6: 218-225.

13) Fokkinga WA, Kreulen CM, Vallittu PK, Creugers NH. A structured analysis of in vitro failure loads and failure modes of fiber, metal, and ceramic post-and-core systems. Int J Prosthodont 2004; 17: 476-482. 
14) Fokkinga WA, Le Bell AM, Kreulen CM, Lassila LV, Vallittu PK, Creugers NH. Ex vivo fracture resistance of direct resin composite complete crowns with and without posts on maxillary premolars. Int Endod J 2005; 38: 230237.

15) Akkayan B, Gulmez T. Resistance to fracture of endodontically treated teeth restored with different post systems. J Prosthet Dent 2002; 87: 431-437.

16) Heydecke G, Butz F, Hussein A, Strub JR. Fracture strength after dynamic loading of endodontically treated teeth restored with different post-and-core systems. J Prosthet Dent 2002; 87: 438-445.

17) Naumann M, Preuss A, Frankenberger R. Load capability of excessively flared teeth restored with fiber-reinforced composite posts and all-ceramic crowns. Oper Dent 2006; 31: 699-704.

18) Sidoli GE, King PA, Setchell DJ. An in vitro evaluation of a carbon fiber-based post and core system. J Prosthet Dent 1997; 78: 5-9.

19) Ferrari M, Vichi A, Mannocci F, Mason PN. Retrospective study of the clinical performance of fiber posts. Am J Dent 2000; 13: 9B-13B.

20) Cormier CJ, Burns DR, Moon P. In vitro comparison of the fracture resistance and failure mode of fiber, ceramic, and conventional post systems at various stages of restoration. J Prosthodont 2001; 10: 26-36.

21) Boschian Pest L, Cavalli G, Bertani P, Gagliani M. Adhesive post-endodontic restorations with fiber posts: push-out tests and SEM observations. Dent Mater 2002; 18: 596-602.

22) Schwartz RS, Robbins JW. Post placement and restoration of endodontically treated teeth: a literature review. J Endod 2004; 30: 289-301.

23) Sirimai S, Riis DN, Morgano SM. An in vitro study of the fracture resistance and the incidence of vertical root fracture of pulpless teeth restored with six post-and-core systems. J
Prosthet Dent 1999; 81: 262-269.

24) Hayashi M, Takahashi Y, Imazato S, Ebisu S. Fracture resistance of pulpless teeth restored with post-cores and crowns. Dent Mater 2006; 22: 477-485.

25) Rosentritt M, Fürer C, Behr M, Lang R, Handel G. Comparison of in vitro fracture strength of metallic and tooth-coloured posts and cores. J Oral Rehabil 2000; 27: 595-601.

26) Krejci I, Duc O, Dietschi D, de Campos E. Marginal adaptation, retention and fracture resistance of adhesive composite restorations on devital teeth with and without posts. Oper Dent 2003; 28: 127-135.

27) Koutayas SO, Kern M. All-ceramic posts and cores: the state of the art. Quintessence Int 1999; 30: 383-392.

28) Zardiackas LD, Disegi J, Givan D. Torsional properties of implant grade titanium. J Biomed Mater Res 1991; 25: 281293.

29) Christensen GJ. Posts: necessary or unnecessary? J Am Dent Assoc 1996; 127: 1522-1524, 1526.

30) Cavel WT, Kelsey WP, Blankenau RJ. An in vivo study of cuspal fracture. J Prosthet Dent 1985; 53: 38-42.

31) St-Georges AJ, Sturdevant JR, Swift EJ Jr, Thompson JY. Fracture resistance of prepared teeth restored with bonded inlay restorations. J Prosthet Dent 2003; 89: 551-557.

32) Eakle WS, Maxwell EH, Braly BV. Fractures of posterior teeth in adults. J Am Dent Assoc 1986; 112: 215-218.

33) Mannocci F, Bertelli E, Sherriff M, Watson TF, Pitt Ford TR. Three-year clinical comparison of survival of endodontically treated teeth restored with either full cast coverage or with direct composite restoration. J Prosthet Dent 2002; 88: 297-301.

34) Siso SH, Hürmüzlü F, Turgut M, Altundaşar E, Serper A, Er K. Fracture resistance of the buccal cusps of root filled maxillary premolar teeth restored with various techniques. Int Endod J 2007; 40: 161-168. 